\title{
Editorial
}

\section{Sobre la importancia de la filosofía en nuestras vidas}

Dairon Alfonso Rodríguez

Universidad Industrial de Santander, Colombia 


\section{Sobre la importancia de la filosofía en nuestras vidas}

\section{About the importance of philosophy in our lives}

Forma de citar (APA): Rodríguez, D. (2019). Sobre la importancia de la filosofía en nuestras vidas. Revista Filosofía UIS, 18(2), doi: 10.18273/revfil.v18n2-2019001

Forma de citar (Harvard): Rodríguez, D. (2019). Sobre la importancia de la filosofía en nuestras vidas. Revista Filosofía UIS, 18(2), 11-16.

Fecha de recepción: 22 de abril de 2019 Fecha de aceptación: 24 de abril de 2019

Dairon Alfonso Rodríguez: colombiano. Doctor en Humanidades. Profesor Universidad Industrial de Santander. Investigador en el grupo de investigación Tiempo Cero de la UIS.

Correo electrónico: darodri@uis.edu.co

ORCID: 0000-0002-5183-7121 


\section{Sobre la importancia de la filosofía en nuestras vidas}

¿De qué se ocupa alguien que se dedica a la filosofía? ¿Cómo lleva a cabo esa persona su particular labor intelectual? Responder a estas preguntas es importante para aclarar la importancia de la filosofía, sus alcances y limitaciones, no solo en relación con las ciencias humanas sino, en general, con respecto al resto de la cultura. Una respuesta apropiada a estas preguntas también será importante para disipar un sin número de mal entendidos que surgen a la hora de hablar de filosofía.

Lo primero que debe aclararse es que la filosofía trata más de problemas que de doctrinas, textos o autores. Insistir en esto es de la mayor importancia, porque nos permite advertir que difícilmente podemos llamar filosófico al ejercicio que se suele hacer en los colegios en Colombia, cuando se repasa la vida y la obra de los diversos filósofos de la tradición occidental. Esta clase de ejercicios, si bien son importantes, suelen olvidar que dichas doctrinas y autores intentaban responder, cada uno a su manera, a problemas que eran vistos por ellos y sus contemporáneos con un fuerte sentido de urgencia. Resolver esos problemas era su principal motivación a la hora de hacer filosofía y, por tanto, toda su obra adquiere sentido cuando se la examina a la luz de esos problemas vitales.

Pero vistos en abstracto, los problemas filosóficos muchas veces pasan como cuestiones que difícilmente afectarían al común de los mortales. Parecerían más bien asuntos de especialistas, de gente ociosa y privilegiada que no se da cuenta de las problemáticas sociales relevantes y que vive aislada en sus centros de estudio. Quizá, el ejemplo más famoso sea el problema medieval relativo a la naturaleza de los ángeles y a la posibilidad de que una multitud de ellos danzasen sobre la punta de una aguja. Es por ello, quizás, que como señala la filósofa inglesa Mary Midgley (2002), estamos acostumbrados a pensar que la filosofía es inútil en el sentido de que sus preocupaciones se encuentran un tanto separadas del resto de nuestras vidas y que por ello es independiente de ella. Pero esta visión de los problemas filosóficos, no pocas veces promovida por los mismos filósofos, pasa por alto aspectos relevantes del funcionamiento del pensamiento y de su relación con la realidad.

En primer lugar, olvida que vivimos en culturas complejas que dependen para su supervivencia de sistemas bastante intrincados de ideas y conceptos, la mayoría de ellas con un claro origen filosófico. Algunas ideas de este tipo son las de democracia, justicia, individuo, racionalidad, progreso, etc., las cuales vieron su amanecer en diferentes momentos de la historia de la filosofía. Cada una de ellas es reconocida por el impacto que ha tenido en nuestro pensamiento cotidiano desde su aparición. Piénsese solamente en la idea, también discutida por Midgley, del contrato social. Dicha idea invierte los términos de la explicación que se solía 
ofrecer de la obligación política. Así, según los filósofos de la Ilustración, la única razón válida para obedecer a cualquier tipo de gobierno es que este representa la voluntad del pueblo soberano y no porque ha sido nombrado por Dios (Rousseau, 1995). Según esta misma narrativa, el pueblo decide libre y racionalmente unirse para formar una sociedad, aceptar unas obligaciones mutuas de convivencia y, finalmente, terminar vinculándose a un gobierno que pueda reforzar esas obligaciones y, si es el caso, hacerlas cumplir por la fuerza. Esta idea, aceptada ampliamente en Europa occidental, ha sido la base de su organización política y jurídica por más de trescientos años y por más simbólica o abstracta que sea, sus consecuencias prácticas y emocionales son innegables.

Por otra parte, la mayoría de las veces, los conceptos filosóficos aparecen en conjunto con otras ideas, formando lo que Midgley llama sistemas de pensamiento (2002). En un sistema de pensamiento, los elementos que lo componen se encuentran fuertemente interconectados de tal forma que constituyen una red en la que las ideas dependen unas de otras para funcionar adecuadamente. Así, el concepto de contrato social no se explica sin otras ideas, quizás aún más abstractas que ella misma, sobre el origen de la sociedad y las capacidades cognitivas de los seres humanos. Thomas Hobbes, filósofo celebérrimo por su visión autoritaria del poder político, explicaba la razón humana por analogía con una calculadora que suma elementos para dar con un resultado (1989). Pero esta idea, lejos de constituir una observación desinteresada sobre el funcionamiento de la cognición humana, busca hacernos creer que los seres humanos, en condiciones normales, jamás optarían por algo que los perjudicara. Esto explica por qué a los ojos de Hobbes resulta no solo inconcebible, sino también imposible, que hombres y mujeres den su consentimiento a una tiranía o gobierno absoluto excepto para escapar de algo aún peor, a saber, el estado de naturaleza, que corresponde a un estado pre-social caracterizado por la guerra de todos contra todos (humanos contra otras especies, humanos contra humanos, hermanos contra hermanos, padres contra hijos, etc.). En este sentido, la idea del contrato social no se explicaría sin otros supuestos aún más abstractos que ella misma. En el sentido inverso, como señala Midgley, "El conjunto de ideas centradas en la imagen del contrato social ha gozado de mucho predicamento, generando brillantes ideas sobre derechos, autonomía, intereses, competencia, la racionalidad como interés propio etc." (2002, p. 21).

Ahora bien, es importante advertir que un sistema de pensamiento influyente no es diseñado conscientemente para operar como un todo coherente y unificado. Más bien, y como lo muestra la historia del pensamiento, dichos sistemas son dinámicos y se reforman constantemente para ajustarse a las necesidades de las sociedades en las cuales se instalan. Así, la red conceptual que servía de fundamento lógico a la idea del contrato social fue modificada en varias ocasiones en los siglos que van desde sus primeras versiones, de la cual la de Hobbes fue una de ellas, hasta sus versiones más aceptadas en la actualidad, como la del filósofo John Rawls (1971). En esta última, por ejemplo, la idea de un estado de naturaleza 
fue abandonada por completo y se le reemplazó por la asunción teórica de que los individuos que toman decisiones racionales dejan de ser egoístas, esto es, olvidan su pasado competitivo. Pero tal y como señala Michael Walzer (2008), la asunción de que los seres humanos no somos aventureros o amantes del riesgo, como lo creyeron los contractualistas utilitaristas como David Hume, sirve probablemente al mismo objetivo que una historia sobre el origen del hombre. Sin embargo, los alcances de una y otra idea son diferentes. Mientras que el estado de naturaleza es la idea que justifica el contrato social como vinculación a un gobierno absoluto, en la historia que nos cuenta Rawls el riesgo de autodestrucción desaparece y más bien se presenta dicho contrato como el resultado lógico o natural del sentido innato de lo justo presente en los seres humanos. Ello da lugar a un gobierno que no necesita ser autoritario para evitar que nos matemos entre nosotros. Por supuesto, el sistema conceptual propuesto por Rawls se ajusta mucho mejor a las sociedades occidentales de nuestros días en las que, tras la Segunda Guerra Mundial, se busca evitar la opresión de las minorías por parte de gobiernos que representan mayorías alienadas.

Pero, en todo lo anterior, ¿dónde aparecen los problemas de los cuales debemos ocuparnos los filósofos? El crecimiento no ordenado de los sistemas de pensamiento hace que con el tiempo los mismos se vuelvan muy intrincados y complejos, monstruos teóricos difíciles de manejar y entender, verbigracia, el liberalismo. A su vez, esta dificultad de los sistemas conceptuales hace que muchas veces prefiramos no prestarles la atención debida. De esa manera se va configurando un círculo vicioso en el que nuestra actitud negligente hacía los sistemas de pensamiento refuerza aún más su tendencia a crecer de manera caótica. Midlegy (2002) señala que tan pronto como este tipo de actitud complaciente se instala en la cultura las confusiones conceptuales comienzan a surgir y con el pasar del tiempo lo único que hacen es agravarse. Esto no sería tan problemático si dichas confusiones no tuvieran repercusiones prácticas y emocionales nefastas. Pensemos, solamente, en lo que ha significado para el liberalismo y para la salud de las democracias occidentales la adopción de ideas provenientes del marketing y la psicología conductista. La incorporación de estas ideas al sistema de pensamiento liberal ha dado lugar a un escenario en el que el fin último de muchos pronunciamientos públicos no es otro que el de manipular a la opinión pública para conseguir la elección de un candidato especifico o la aprobación de ciertas medidas inicialmente impopulares. Naturalmente, el sentimiento que generan estas prácticas generalizadas, afianzadas a través de las escuelas de gobierno y ciencia política de todo el mundo, no es otro que el de la desconfianza en las instituciones democráticas y la política en general (Botero, 2018). Este es uno de los factores que explicaría cómo, por ejemplo, Donald Trump logró ganar en el último minuto la presidencia de los Estados Unidos al revelar que su contrincante Hillary Clinton, siguiendo los manuales básicos de Ciencias políticas, había ocultado información sensible cuando ella ocupó la Secretaría de Estado. Pero volvamos a la filosofía. Su labor entonces consistiría en rastrear y detectar 
aquellos conceptos que al ser introducidos subrepticiamente no nos damos cuenta de que causan problemas reales. Una vez el filósofo ha ubicado la fuente del problema procede a abordarlo como quien trata una enfermedad: propone una cura que no es otra que la eliminación de los conceptos problemáticos, al tiempo que los reemplaza por otros nuevos y mejor ajustados a las necesidades sociales del momento. Es aquí, en esta labor terapéutica, donde residiría la importancia de la filosofía para nuestras vidas.

\section{Referencias}

Botero, A. (2018). La tragedia moderna: las elecciones políticas vistas desde el cine. En D. Hincapié y L. Castro (coords.), Filosofía del derecho GlocAL (pp. 73-109). Bogotá: Universidad Nacional de Colombia.

Hobbes, T. (1989). Leviatán. Madrid: Alianza.

Midgley, M. (2002). Delfines, sexo y utopías: doce ensayos para sacar la filosofía a la calle. Madrid: Turner.

Rawls, J. (1971). Teoría de la justicia. Ciudad de México: Fondo de Cultura Económica.

Rousseau, J. J. (1995). El contrato social o Principios de derecho político. Madrid: Tecnos.

Walzer, M. (2008). Contrato Social. En T. Honderich, Enciclopedia Oxford de filosofía. Madrid: Tecnos. 